\title{
PENGARUH PENDEKATAN TAKTIS TERHADAP KETERAMPILAN PASSING BOLA PADA SEKOLAH SEPAKBOLA TURANGGA SAKTI
}

\author{
Yosi Iskandar ${ }^{1)}$, Boby Agustan $^{2)}$ \\ ${ }^{1}$ STKIP Muhammadiyah Kuningan \\ email: iskandar.yosi@gmail.com \\ ${ }^{2}$ STKIP Muhammadiyah Kuningan \\ email: bobyagustan@gmail.com
}

\section{Info Artikel}

Sejarah Artikel:

Diterima Desember 2017

Disetujui Desember 2017

Dipublikasikan Januari 2018

Keywords:

Pendekatan, taktis, keterampilan, passing.

\section{Abstrak}

Pengaruh Pendekatan Taktis Terhadap Keterampilan Passing pada Siswa Turangga Sakti. Penelitian ini bertujuan untuk mengetahui pengaruh pendekatan taktis terhadap keterampilan passing dalam sepak bola di sekolah sepakbola Turangga Sakti. Penelitian ini menggunakan penelitian eksperimen, dengan membagi menjadi dua kelas, yaitu kelas kontrol dan kelas eksperimen. Kelas kontrol dengan tidak ada perlakuan pendekatan taktis dan kelompok eksperimen dengan perlakuan pendekatan taktis. Populasi dan sampel dalam penelitian ini adalah siswa sekolah sepakbola Turangga Sakti yang berjumlah 96 siswa. Instrumen yang digunakan adalah tes keterampilan passingdengan melakukan teste dengan jarak 4 meter dengan durasi waktu 30 detik yang dilakukan dilapangan dan diruangan. Analisis data menggunakan uji $t$ dan persentase. Hasil pengujian menunjukkan ada perbedaan pengaruh yang signifikan pada hasil pre tes dan post tesdengan $t$ uji $t$ didapat nilai $t=2.349$ dengan derejat kebebasan $n 1+n 2-2=48+48-2=94$ dan $p$-value (2-tailed) $=0,021$. Uji hipotesis yang dilakukan adalah hipotesis satu sisi nailai $p$ value (2-tailed) dibagi menjadi $2.349: 2=0,11745$ karena harga $p$-value $=0,11745$ lebi kecil dari $\alpha=0,05$ maka Ho ditolak. Artinya ada pengaruh penerapan pendekatan taktis terhadap keterampilan passing siswa Sekolah Sepakbola Turangga Sakti.

\begin{abstract}
Effect of Tactical Approach on Passing Skills in Turangga Sakti Students. This study aims to determine the effect of tactical approaches to passing skills in soccer at the Turangga Sakti soccer school. This study uses experimental research, by dividing it into two classes, namely the control class and the experimental class. Control class with no tactical approach and experimental group treatment with tactical approach treatment. The population and samples in this study were students of the Turangga Sakti football school, which numbered 96 students. The instrument used was a
\end{abstract}


passing skills test by performing a test with a distance of 4 meters with a duration of 30 seconds which was carried out in the field and in the room. Data analysis using $t$ test and percentage. The test results showed that there were significant differences in the results of the pre-test and posttest with the $t$-test obtained by $t=2.349$ with the freedom of $n 1+n 2-2=$ $48+48-2=94$ and $p$-value $(2$-tailed $)=0.021$. The hypothesis test was carried out by the one-sided hypothesis that p-value (2-tailed) was divided into 2,349: $2=0.11745$ because the price of $p$-value $=0.11745$ was smaller than $\alpha=0.05$, so Ho was rejected. This means that there is the effect of applying a tactical approach to the passing skills of students of the Turangga Sakti Soccer School.

(C) 2019 Yosi Iskandar, Boby Agustan Under the license CC BY-SA 4.0

$\bowtie$ Alamat korespondensi: ISSN 2443-1117 (cetak)

E-mail : bobyagustan@gmail.com

No Handphone : 085224311903 


\section{PENDAHULUAN}

Sepak bola adalah suatu permainan beregu yang terdiri dari sebelas orang pemain termasuk seorang penjaga gawang. Sepak bola adalah permainan yang sangat populer. Permainan sepakbola sering dilakukan oleh anak-anak, orang dewasa maupun orang tua. Tujuan dari permainan sepak bola adalah masing-masing regu atau kesebelasan berusaha untuk menguasai bola, memasukkan bola ke dalam gawang lawan sebanyak mungkin, dan berusaha mematahkan serangan lawan untuk melindungi atau menjaga gawangnya agar tidak kemasukan bola. Permainan sepakbola merupakan permainan beregu yang memerlukan dasar kerjasama antar sesama anggota regu, sebagai salah satu ciri khas dari permainan sepak bola.

Layaknya sebuah pabrik pembinaan usia muda perlu dikelola secara lebih terencana dan sistematis. Sehingga secara presisi menghasilkan pemain sesuai dengan tuntutan sepak bola modern. Dalam pembinaan usia muda sangat didukung oleh berbagai unsur yang terkait, baik dari orang tua, sekolah, ataupun lembaga pengayom sepakbola, dalam hal ini adalah PSSI. Terutama PSSI dan para pembina sepak bola usia muda perlu menyesuaikan metode, sistem, dan kurikulum latihan di sekolah-sekolah sepak bolanya agar berjalan seiring dengan perkembangan sepak bola modern.

Pembinaan usia dini sangatlah penting dalam pembentukkan pondasi awal atlet dalam berprestasi pada masa yang akan datang. Pembinaan usia dini yang baik sesuai dengan sistem dan kurikiulum pada jenjang usianya akan menunjang perkembangan pada atlet sepak bola. Konsistensi pembinaan usia dini tersebut telah ditunjukkan oleh SSB Turangga Sakti dengan berbagai pembinaan di berbagai jenjang usia yang disesuaikan dengan kurikulumnya.Sekolah sepak bola atau SSB mempunyai peranan yang dominan karena dalam proses latihan atlet mempunyai waktu yang cukup dalam mengenal sepak bola. Dalam pelatihan di sekolah sepak bola kemampuan teknik dasar sangatlah diperlukan dalam pembentukan pondasi awal kemampuan atlet. Untuk dapat bermain sepak bola dengan baik atlet harus mempunyai keterampilan teknik dasar yang baik. Sucipto (2007:2) memaparkan bahwa pada teknik-teknik dasar dalam permainan sepakbola ada beberapa macam, seperti 1) stop ball (menghentikan bola), 2) shooting (menendang bola ke gawang), 3) passing (mengumpan), 4) heading (menyundul bola), dan 5) dribbling (menggiring bola).

Pendapat di atas menjelaskan bahwa teknik tersebut haruslah dimiliki oleh seorang pemain sepak bola, artinya seorang pemain akan berhasil dalam sepak bola ketika dalam prakteknya menggunakan teknik dasar yang sudah diberikan oleh pelatih.Salah satu teknik dasar yang harus dikuasai atlet agar dapat bermain bola dengan baik adalah passing. Teknik passing dilakukan secara terus menerus sesuai dengan permainan di setiap babak. Dengan demikian maka tehnik passing yang baik dan tepat sangat diperlukan, agar mampu melakukan operan yang baik, tepat, dan akurat dalam tempo tinggi tanpa mengalami kesulitan yang berarti. Dalam teknik passing setidaknya ada tiga teknik dasar, sebagaimana diungkapkan Luxbacher ( 1997 : 11-12) adalah sebagai berikut:

1. Inside-of- the-foot (dengan bagian samping dalam kaki);

2. Outside-of-the-foot (dengan bagian samping luar kaki);

3. Instep (operan ini sering diseup dengan kura kura kaki yang merupakan bagian dari kaki yang ditutupi dengan tali sepatu yang menyediakan permukaan yang keras dan rata untuk menendang bola.

Teknik dasar tersebut di atas harus dikuasai dengan benar oleh pemain sepak bola guna meloloskan diri dari pemain yang menempel ketat. Bagi seorang pemain sepak bola passing merupakan kemampuan 
fital agar dapat memberi umpan dan membuka ruang gerak bagi pemain lain. Selain itu passing merupakan keterampilan dasar dalam sepak bola karena pemain harusmampu mengoper pada saat bergerak, berdiri, atau bersiap melakukan tembakan. Ketika pemain sudah mampu dan menguasai kemampuan passing secara efektif, seorang pemain akan berpengaruh besar dalam sebuah club dalam melakukan permainan sepak bola.

Pelatih SSB harus dapat menciptakan suasana pelatihan yang dapat memotivasi siswa yang dilatihnya. Suasana tersebut secara psikologi dapat mempengaruhi siswa terhadap tugas-tugas yang dilakukannya dalam melatih sepak bola, seperti penjelasan materi apa yang diberikan pelatih, mengapa dan untuk apa hal itu dikerjakan, serta bagaimana keterkaitan dengan permainan sesungguhnya. Nuansa pelatihan tersebut haruslah ditanamkan oleh pelatih dari sejak dini agar para siswa mudah memahami dan menerima makna serta esensi dari pelajaran yang diberikan oleh sang pelatih, sehingga siswa dapat dengan mudah mengaplikasikan teori tersebut dilapangan.

Untuk merealisasikan hal tersebut di atas, seorang pelatih dituntut untuk menggunakan sebuah model atau pendekatan yang cocok dalam memberi materi pelatihan sepak bola, salah satunya dengan pendekatan taktis. Penedekatan taktis menurut Sucipto adalah "tujuan pendekatan agar siswa mampu memadukan pengasaan teknik dasar yang dipelajari dengan kemampuan teknik bermainnya sejalan dengan meningkatnya teknik dasar yang dimilikinya". Pendapat di atas menekankan terhadap sebuah permainan sekaligus dapat meningkatkan teknik dasar yang berkaitan dengan bentukpermainannya, sehingga diharapkan siswa dapat memahami relevansi pelatihan teknik dasar terhadap situsi-situsai di dalam permainan yang sebenarnya. Apabila pendekatan taktis tersebut dapat diterapakan dalam sebuah latihan maka besar kemungkinan siswa lebih antusias, tertarik, dan termotivasi untuk berferan aktiktif dalam mengikuti pelatihan sepak bola, khususnya di SSB Turangga Sakti.

\section{Lebih lanjut Subroto (2001: 6)} menjelaskan bahwa penekatan taktis atau juga disebut pendekatan tradisional adalah: "Pendekatan taktis atau pendekatan tradisonal untuk mengajarkan permainan yang menekankan pada penguasaan keterampilan teknik dasar. Dijelaskan pula penedekatan tradisional menekankan pada penguasaan teknik dasar secara terpisah. Dengan demikian pelatihan dengan pendekatan teknik mengajarkan teknikteknik dasar secara terpisah pada pelaksanaan permainan sesungguhnya”.

Hal ini sesuai dengan pengamatan dan observasi awal yang mengisyaratkan bahwa dalam proses pelatihan jangan terlalu menggunakan pendekatan yang 
sifatnya tradisional sehingga tidak akan muncul permasalahan pelatihan yang kurang memotivasi siswa yang dilatihnya. Hal ini terjadi karena masih digunakan sistem pendekatan pelatihan dan pembelajaran yang kurang relevan dengan materi yang akan dilatihkan. Penulis merasa terketuk hati untuk berperan aktif di SSB Turangga Sakti dengan menggunakan penerapan pendekatan taktis terhadap keterampilan passing.

Penerapan pendekatan taktis merupakan salah satu upaya untuk mengatasi kesulitan siswa dan mengasah keterampilan passing di SSB Turangga Sakti. Oleh karena itu penulis akan melakukan penelitian tentang permasalahan di atas, dengan judul penelitian: Pengaruh Pendekatan Taktis Terhadap Keterampilan Passing dalam Sepak Bola di Sekola Sepak Bola Turangga Sakti.

\section{METODE PENELITIAN}

Metode penelitian yang digunakan penulis untuk menguji kebenaran hipotesis yang telah diajukan adalah metode eksperimen. Desain Penelitian berfungsi untuk memberikan jalan dan arah proses penelitian yang dilakukan. Mengenai definisi penelitian ini Nasution (2004:40) menyatakan bahwa: "Desain Penelitian merupakan suatu rencana tentang cara mengumpulkan dan menganalisis data sesuai dengan tujuan penelitian". Dalam penelitian ini desain penelitian yang digunakan adalah One Group Pre-test and Post-test Design. Sugiyono (2009:5). Populasi pada penelitian ini adalah siswa kelas XI IPA 1 MAN 1 Kuningan dengan jumlah 40 siswa. Sedangkan sampel penelitian sebanyak 20 siswa laki-laki, dan teknik pengambilan sampel menggunakan purposive sampling. Sesuai dengan pendapat Sugiyono (2009: 82) mengatakan bahwa "teknik Purposive sampling digunakan untuk menentukan sampel penelitian dengan beberapa pertimbangan tertentu yang bertujuan agar data yang diperoleh bisa lebih representatif". Instrumen penelitian menggunakan adalah tes passing and stopping sepakbola. (Nurhasan, 2007:207). Teknik analisis data yang digunakan dalam penelitian: 1) Uji prasyarat analisis: a. uji normalitas b. uji homogenitas. 2) Uji hipotesis menggunakan uji-t (t-test).

Metode yang digunakan adalah metode eksperimen lapangan. Populasi yang diambil adalah anak SSB yang berjumlah 96 anakdi SSB Turangga sakti. Jadi teknik pengambilan sampel dalam penelitian ini adalah total sampling, dengan jumlah sampel yang digunakan dalam penelitian ini adalah sebanyak 96 anak yang aktif berlatih.

Instrumen penelitian yang digunakan untuk pengumpulan data dalam penelitian ini adalah tes. Alat bantu yang digunakan untuk mengukur hasil besaran pengaruh penerapan pendekatan taktis terhadap keterampilan passing dalam sepak bola di SSB Turangga Sakti.

Adapun instrumen penelitian ini mengacu pada pendapat Nurhasan dkk (2007: 207) sebagaiamana terlihat dibawah ini.

1. Tes Passing Sepak Bola

a) Tujuan : mengukur keterampilan dan gerak kaki dalam menyepak bola. 
b) Alat yang digunakan adalah bola sepak dan stop watch.

2. Petunjuk pelaksanaan:

a) Teste berada di tengah lapangan yang berjarak 4 meter.

b) Pada aba-aba "ya" teste mulai menyepak bola ke tembok.

Gambar 3.1 Instrumen Penelitian TesPassing Sepak Bola

Menurut Nurhasandkk (2007 : 207)

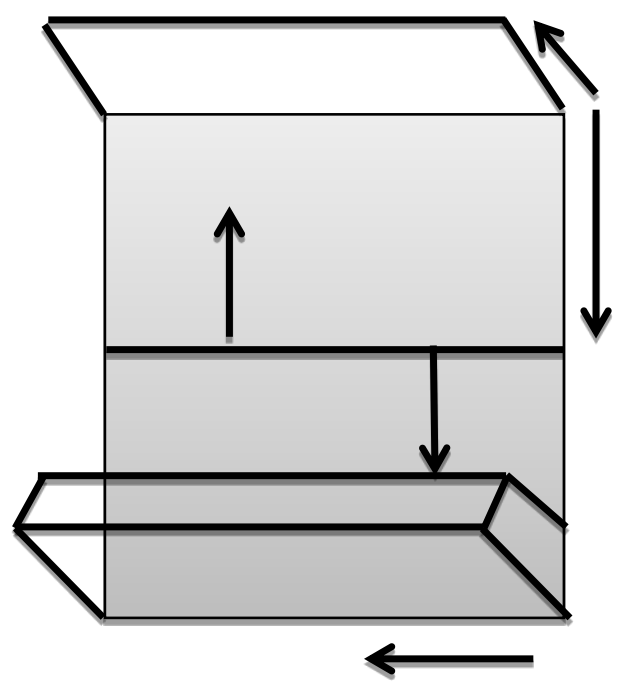

c) Lakukan kegiatan ini selama 30 detik.

d) Apabila bola keluar dari daerah sepak, maka teste menggunakan bola cadangan.

Semua kegiatan tes tersebut dilakukan dilapangan sebagaimana terlihat dalam gambar dibawah ini :

\section{HASIL DAN PEMBAHASAN}

Setelah data diketahui berdistribusi normar dan homogen, ,maka dilanjutkan melakukan analisis uji t. Untuk mengetahui pengaruh pendekatan taktis terhadap keterampilan passing dalam sepak bola di SSB Turangga Sakti dilakukan analisis hasil eksperimen yang menggunakan pretest dan post-test one group design dengan megunakan analisis uji t untuk mengetahui apakah terdapat pengaruh antara hasil pre test dan post test yang telah dilakukan untuk mengetahui keterampilan passing sesudah dan sebelum perlakuan pendekatan taktis.

Hasil uji $t$ dalam penelitian ini menggunakan uji indefendent sampels test, yang disajikan dalam tabel berikut ini: 
Tabel 1 Hasil Uji Indefendent Samples Tes

\begin{tabular}{cccccc}
\hline \multicolumn{5}{c}{ Group Statistics } \\
\hline \multirow{2}{*}{ Gain } & Group & $\mathrm{n}$ & Mean & Std. Deviation & Std. Error Mean \\
\cline { 2 - 6 } & Eksperimen & 48 & 46.15 & 18.492 & 2.669 \\
\cline { 2 - 6 } & Kontrol & 48 & 35.65 & 20.158 & 2.910 \\
\hline
\end{tabular}

\section{Independent Samples Test}

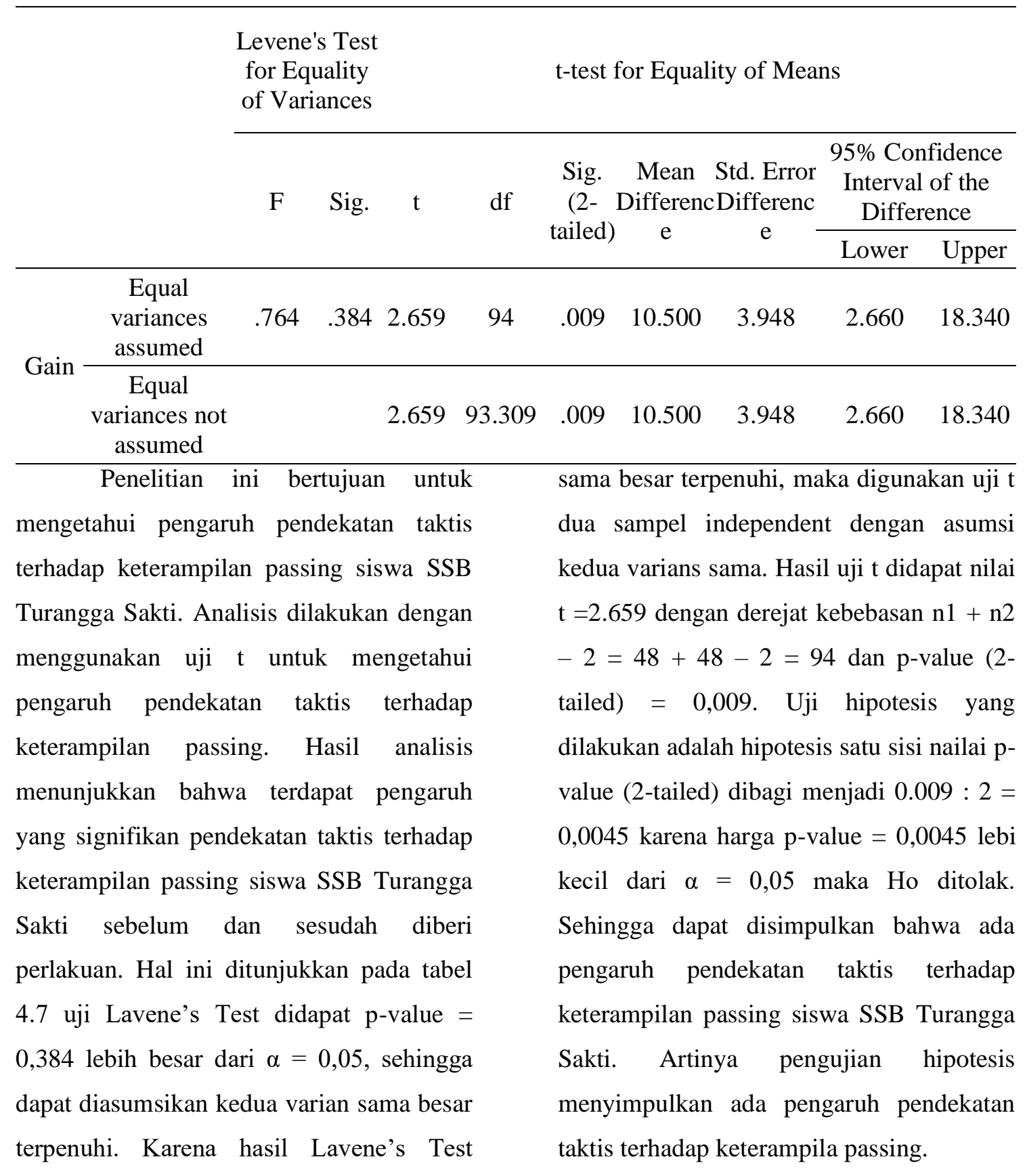


Keterampilan passing adalah salah satu teknik dasar dalam permainan sepak bola untuk membuat pemain sepak bola menjadi profesional dengan membuat mereka berlatih secara kontinue sebelum ada bimbingan dari pelatih. Startegi ini dapat meningkatkan motivasi siswa SSB untuk terus meningkatkan kemampuan dan skill sepak bola khususnya dalam keterampilan passing.

Keterampilan pada hakekatnya adalah kemampuan, dapat dipandang sebagai refleksi dari proses berlatih yang benar-benar setiap individu sedangkan skill merupakan cerminan kemampuan seorang dalam merepleksikan kemampuan dalam realisasi dilapangan.

Penelitian tentang pengaruh penerapan pendekatan taktis terhadap keterampilan passing yang dilakukan pada siswa SSB Turangga Sakti. Pengaruh pendekatan taktis secara statistik mempunyai nilai signifikansi adalah $0,0049<$ dari $\alpha=0,05$, artinya penerapan pendekatan taktis ini bermakna dapat meningkatkan keterampilan passing, kecilnya angka yang diperoleh peneliti berpendapat bahwa selain pendekatan taktis ada faktor lain yang berpengaruh terhadap keterampilan passing siswa SSB Turangga Sakti.

Faktor-faktor yang dapat mempengaruhi peningkatan keterampilan passing tersebut peneliti berpendapat diantaranya adalah yang pertama adalah setiap hari berlatih dasar-dasar sepak bola. Meningkatkan kualitas penguasaan teknik dasar kita seperti yang disebutkan diatas. Lakukan minimal 30 menit setiap harinya. Latihan tiap hari biarpun sebentar lebih bagus daripada latihan lama tapi seminggu sekali. Dengan latihan setiap hari akan melatih kaki anda, dan melatih pikiran anda. Jika teknik ini dilakukan secara regular akan mendapatkan kemajuan yang lebih cepat. Faktor kedua rasakan bola dengan kaki. Ketiga latihan passing dengan ukuran bola yang berbeda. Latihan menendang dengan bola kecil misalnya bola tenis, akan membantu meningkatkan keterampilan bola anda. Dan saat dalam pertandingan kita akan merasa jauh lebih mudah mengontrol bola normal, karena terbiasa latihan dengan bola yg lebih kecil, yang lebih sulit kontrolnya dan faktor atihan mengoper bola ke teman secara cepat. Mengoper bola ke teman bergantian dengan kaki kanan dan kiri, usahakan juga jarak teman anda bervariasi, kadang jauh kadang dekat. Latihan ini berguna untuk mempertajam passing pemain.

Hasil penelitian ini bahwa penerapan pendekatan taktis dapat digunakan dalam proses berlatih dalam sepak bola dengan melihat kelebihan pendekatan ini. Dalam penerapannya pendekatan taktis ini terdapat hal yang perlu diperhatikan diantaranya adalah kesiapan pelatih dalam melatih siswanya dengan teknik yang bervariatif dan kemampuan pelatih dalam mengembangkan materi dan teknik-teknik latihan. 


\section{SIMPULAN}

Berdasarkan hasil pengolahan dan analisis data, maka kesimpulan dari hasil penelitian ini adalah sebagai berikut:

1. Pengaruh penerapan pendekatan taktis terhadap keterampilan passing dalam permainan sepak bola di ssb turangga sakti bertujuan untuk memadukan penguasan teknik dasar yang dipelajari dengan kemampuan bermainnya wekaligus untuk menanamkan keyakinan terhadap diri siswa untuk dapat menerapkan taktik bermainnya sejalan dengan meningkatnya teknik dasar yang dimilikinya. Apabila metode pendekatan taktis diterapkan pada pelatihan sepak bola, maka besar kemungkinan siswa akan lebih antusias, tertarik, dan termotivasi untuk berpartisipasi aktif dalam pelatihan yang diikutinya.

2. Pelaksanaan keterampilan passing pada siswa ssb turangga sakti yang dilaksanakan oleh pelatih tidak terlepas dari konsep passing itu sendiri, dengan memindahkan bola mendatar atau di udara dari satu pemain ke pemain lainnya dengan jarak yang bervariasi. Konsep tersebut dikonversi kedalam jenis passing yaitu, umpan 1- 2 (wall pass), umpan terobosan (through pass), crossing, dan back pass. Konsep tersebut tersebut digunakan pelatih ternyata sangat simpel dan siswa ssb cepat menerimanya.

Hasil dari penerapan pendekatan taktis ini keterampilan passing siswa ssb turangga sakti ini mengalami peningkatan yang signifikan dengan hasil uji t didapat nilai $\mathrm{t}=2.659$ dengan derejat kebebasan $\mathrm{n} 1$ $+\mathrm{n} 2-2=48+48-2=94$ dan p-value (2tailed) $=0,009$. Uji hipotesis yang dilakukan adalah hipotesis satu sisi nilai $\mathrm{p}$ value (2-tailed) dibagi menjadi $0.009: 2=$ 0,0045 karena harga $p$-value $=0,0045$ lebi kecil dari $\alpha=0,05$ maka ho ditolak. Artinya ada pengaruh pendekatan taktis terhadap keterampilan passing siswa ssb turangga sakti.

\section{DAFTAR PUSTAKA}

Arends, Richard.(2008). Learning to Teach: Belajar untuk Mengajar. Yogyakarta Pustaka Pelajar.

C. Asri Budiningsih. (2006). Strategi Pembelajaran. Yogyakarta: FIP UNY.

Jumhana, J., \& Agustan, B. (2016). Pengaruh Model Directinstruction Terhadap Teknik Dasar Dribbling Dalam Permainan Sepak Bola. JUARA : Jurnal Olahraga, 1(1), 4650. doi:10.33222/juara.v1i1.57

Justinus Lhaksana.(2012) .Taktik dan Strategi Futsal modern.Depok: Be Champion.

Komarudin. (2005). Diktat Pembelajaran Dasar Gerak Sepakbola. Yogyakarta: Program Studi Pendidikan Jasmani Kesehatan dan Rekreasi. Jurusan Pendidikan Olahraga. FIK UNY

Murhananto.(2006). Dasar-dasar Permainan Futsal (Sesuai dengan Peraturan FIFA). Jakarta: PT. Kawan Pustaka.

Nurhasan. 1999. "Tes dan Pengukuran". Yogyakarta: Kanisius.

Nanang Riyadi. (2013). Tingkat Keterampilan Kemampuan Dasar Bermain Futsal yang Menggunakan Lapangan Agung Futsal Jatianom Klaten.Skripsi. Yogyakarta: FIK UNY.

Nurhasan. (2001). Tes dan pengukuran Dalam Pendidikan Jasmani: Prinsip-Prinsip dan Penerapannya. Jakarta: Depdiknas.

Ramadan, G. (2017). Pengaruh Metode Pembelajaran Dan Motivasi Belajar Terhadap Hasil Belajar Passing Sepakbola. JUARA : Jurnal 
Olahraga, $\quad 2(1), \quad$ 1-10. doi:10.33222/juara.v2i1.27

Rusman. (2011). Model-model Pembelajaran Mengembangkan Profesionalisme Guru. Jakarta: Rajawali Press.

Rusmono. (2012). Strategi Pembelajaran dengan Problem based Learning Itu Perlu untuk meningkatkan profesionalitas Guru. Bogor: Ghalia Indonesia

Luxbacher. Joseph.1997. Sepak Bola. Langkah-langkah Menuju Sukses. Jakarta: PT. Raja Grafindo Persada.
Subroto. 2001. Pembelajaran Keterampilan dan Konsep Olah Raga Di Sekolah Dasar Sebuah Penekatan Permainan Taktis. Jakarta. Depdiknas. Dirjen Pendidikan dasar dan Menengah.

Sucipto, dkk. 2000.Sepakbola.Yogyakarta: Departemen Pendidikan dan Kebudayaan.Justinus Lhaksana Ishak H. Pardosi.(2008) .Inspirasi dan Spirit Futsal. Jakarta.

Sahda Halim. (2009). .1 hari pintar main futsal.Yogyakarta: Penerbit Media presindo. 